\title{
¡Que cada bala sea un velorio! Agencia y violencia en el mundo de los vaqueros de la Serranía del Manacacías
}

Let every bullet be a wake! Agency and violence in the world of cowboys of the Manacacías mountain range

\section{RESUMEN}

Se busca presentar una reflexión sobre las maneras como es experimentada la violencia por parte de los vaqueros desde la memoria del territorio en los caminos y las posadas ganaderas, en el marco de un proceso de investigación sobre los lugares de práctica del arreo. El análisis fue abordado desde la agencia, entendida como las fuerzas y secuencias causales ejercidas entre los actores y los lugares donde han desempeñado su oficio los vaqueros. La investigación fue de corte cualitativo aplicando un método etnográfico en la Serranía del Manacacías en el departamento del Meta, Colombia. Como resultado se encontró que la violencia como agente, ha determinado un modo de vida y una cotidianidad en el presente, con relación a la cultura de tradición ganadera. Se ha concluido que estos hechos modelan en gran medida el territorio de los vaqueros, así como las relaciones sociales y procesos de normalización de la violencia.

Palabras clave: agencia, violencia, caminos ganaderos, posadas ganaderas, vaqueros, memoria.
Jhon Moreno-Riaño

Magíster en Patrimonio Cultural de la Universidad Pedagógica y Tecnológica de Colombia. Grupo de investigación: Grupo Interdisciplinario de Investigaciones Arqueológicas e Históricas de la UPTC, Tunja, Boyacá, Colombia.

$\square$ corpcultemt@gmail.com

(1D) ORCID: 0000-0002-9317-0206

ज̂ Google Scholar 


\begin{abstract}
The objective of this article is to reflect on the ways in which violence is experienced by cowboys from the memory of the territory on the roads and livestock inns, within the framework of a research process on the places of roundup practice. The analysis was approached from the agency, understood as the forces and causal sequences exerted between the actors and the places where they have worked as cowboys. The research carried out was qualitative, applying an ethnographic method in the Manacacías mountain range in the Department of Meta, Colombia. As a result, it was found that violence, as an agent, has determined a way of life and a daily life in the present, in relation to the culture of livestock tradition. It has been concluded that these facts largely shape the territory of cowboys, as well as social relations and violence normalization processes.
\end{abstract}

Keywords: agency, violence, livestock roads, livestock inns, cowboys, memory.

\title{
Introducción
}

a Serranía del Manacacías en el departamento del Meta, Colombia, ha sido un territorio en disputa desde la conquista: de un lado los buscadores de oro del Ariari que en el siglo XVII apropiaron territorios fundando poblaciones como La Fragua; de otro, los grandes terratenientes que en el siglo XVIII apropiaron sabanas desarrollando la ganadería extensiva. Más tarde, los terratenientes prevalecieron y heredaron la tradición ganadera de las haciendas jesuitas, generando un universo cultural asociado a ese tipo de explotación ganadera, que se ha extendido hasta nuestros días y es el contexto en que surge una cultura ganadera que tiene a los cantos de trabajo de llano como una de sus prácticas. En el siglo XX esta Serranía fue territorio de paso para las migraciones del auge cauchero, la coca y la marihuana. Así, hasta los desplazamientos en la segunda mitad del siglo XX por las guerras entre liberales y conservadores, FARC, paramilitares, desempleo, explotación petrolera y monocultivos.

Desde la perspectiva de Gell (2016), se analizan las principales fuerzas o secuencias causales, entendidas como la agencia que se ejerce entre los sujetos y que ejercen los objetos, los eventos de violencia y los lugares en el desarrollo del oficio de los vaqueros. Esta agencia conlleva además una incidencia en los procesos de transmisión de prácticas culturales importantes para estas comunidades, asociadas a sus modos de vida 
(PEScU, 2013), por cuanto ha generado el abandono gradual del oficio del arreo de ganados durante el cual se practican los cantos de cabrestero y arreo, así como también el abandono de la ganadería como actividad económica, optando por vender o alquilar los antiguos hatos a empresas palmeras, generando transformaciones en el territorio de la Serranía del Manacacías.

Las transformaciones de esos contextos y de sus significados constituyen índices intangibles y materiales, análogos a la manera propuesta por Gell (2016) con las obras de arte. En otras palabras, estos contextos y sus relatos y objetos ejercen un poder, suscitan operaciones cognitivas que implican la abducción de la agencia de los individuos en una cadena de causalidades, de la misma manera en que un individuo ejerce efectos sobre otro individuo o conjunto de individuos en un tejido social. Siguiendo esta idea, la agencia es abordada en este texto como "la capacidad que poseen las personas o cosas de provocar secuencias causales de un tipo particular, sucesos no sólo físicos sino también causados por actos mentales, de voluntad o de intención" (Malosetti-Costa, 2016, p. 170).

Se plantea una reflexión centrada en relatos, caminos y posadas a partir de la activación de la memoria con un grupo de vaqueros que han formado parte de este trabajo de investigación, en relación con los procesos de violencia y su papel en la construcción social de este territorio. Los hatos y caminos ganaderos constituyen lugares importantes y son centro del análisis por ser considerados por los vaqueros como escenarios de sus principales prácticas y donde se han transmitido sus saberes para la adaptación al medio. El trabajo de llano y el oficio de los vaqueros comprenden todas las prácticas asociadas a la ganadería extensiva de bovinos y a su relación con los caballos, que ha permitido desarrollar el canto y las sonoridades como medio para articular las relaciones sociales y las relaciones hombre-animal. Los cantos de trabajo de llano, además, han sido incluidos en 2017 por la UNESCO en la Lista de Salvaguardia Urgente del Patrimonio Cultural Inmaterial de la Humanidad (UNESCO, 2017), y en medio del trabajo de investigación relacionado con sus lugares de práctica, ha surgido la violencia como una categoría saliente en la configuración cotidiana del oficio, del camino y las posadas.

La construcción social de este territorio ha sido determinada de manera preponderante desde su actividad económica basada en la ganadería; actividad que ha generado un mundo de significados y de imaginarios asociados al lugar. Estos contextos han demandado necesidades que se han venido supliendo a través de oficios desarrollados a lo largo de más de 200 años por sus pobladores, en respuesta a unas problemáticas de 
subsistencia, generando modos de vida comunes y saberes colectivos alrededor de la actividad ganadera que ha conectado el territorio por medio de caminos. Todos estos elementos, oficios y actividades, son entonces entendidos como generadores de memoria de un territorio, escenario de diversas manifestaciones culturales interconectadas por la red caminos ganaderos, y por las redes de relaciones entre las comunidades que lo componen.

El camino es el articulador, Colombia se ha venido construyendo con base en caminos. Caminos de todo tipo: reales, secundarios, terciarios, provisionales, etc. "Todo, en los más diversos órdenes, parece depender de ese milagro sencillo atesorado por el hombre desde siempre: el camino" (Ferro, 1994, p. 8). El camino ganadero constituye una serie de líneas que atraviesan el espacio físico conectando puntos de especial importancia que son hatos y posadas ganaderas ubicadas estratégicamente con base en un desarrollo histórico del territorio, y que se materializan como lugares de memoria, puesto que "la memoria no solo está en los ríos, en el mar, en las haciendas. [...] otros escenarios también son espacios llenos de historias, de memoria [...]" (Hoffmann, 2000, p. 3). La construcción social del territorio es entonces un proceso inacabado, en el marco de los acelerados cambios en los usos de la tierra, de múltiples momentos de violencia y de "la contracción espacio-temporal, la multiplicación de los flujos, comunicaciones y redes, que han llevado a una intensa interacción cultural provocando procesos tanto de homogenización, como de desterritorialización, reterritorialización e hibridación" (Appadurai, 1996; García-Canclini, 1999, en Santamarina-Campos, 2013, p. 265).

En el proceso histórico la Serranía del Manacacías se ha desarrollado de manera importante, teniendo a la ganadería extensiva como principal actividad socioeconómica desde la época colonial (Rausch, 1994). Desde entonces se han producido importantes transformaciones relacionadas con la violencia ejercida por distintos actores y asociada a procesos de distribución y apropiación de la tierra, a la explotación minera, al auge de monocultivos - desde el caucho hasta la palma de aceite- y a la proliferación del narcotráfico especialmente en los últimos 40 años. El contexto de violencia generado por estos factores ha sido una constante y ha constituido una forma de vida que transforma las costumbres y la cotidianidad de sus habitantes. Esto hace que se centre la atención en el mundo de los trabajadores de llano o vaqueros, que han sido afectados por diversas violencias a través del tiempo y, que a su vez hacen parte del grupo de portadores de los cantos de trabajo de llano (PEScU, 2013), con quienes se ha llevado a cabo un complejo proceso de implementación del plan especial de salvaguardia de esta manifestación en el territorio. 
El trabajo para los vaqueros es un valor fundamental. Se valora especialmente la actividad relacionada por siglos con la tradición ganadera, el denominado trabajo de llano y sus cantos, que hacen parte de las herramientas usadas en este contexto, y que están "asociados a las actividades tradicionales de la ganadería extensiva que se desarrollan en la región desde el siglo XVII y con mayor auge durante los siglos XIX y XX" (PEScU, 2013, p. 11).

Este trabajo de investigación es enfocado en el mundo de un grupo de vaqueros de San Martín de los Llanos, donde se destacan al menos dos características: ocho vaqueros veteranos, retirados, de entre 70 y 90 años de edad, y otro grupo de ocho vaqueros activos, de entre 40 y 70 años de edad. Con ellos se ha desarrollado una experiencia etnográfica, teniendo en cuenta que "... toda investigación no es más que la mirada de un sujeto histórica y culturalmente localizado..." (García, 2012, p. 27) y, que por tanto se volverá constantemente sobre la reflexión subjetiva que interpela el análisis que se lleva a cabo por parte del investigador.

Esta investigación fue realizada en los caminos y posadas ganaderas de la Serranía del Manacacías que comprende el municipio de San Martín de los Llanos y pequeñas fracciones de Guamal, Castilla la Nueva, San Carlos de Guaroa, Puerto López, Puerto Gaitán, San Juan de Arama, Fuente de Oro, Puerto Lleras, Mapiripán y Granada.

\section{Agencias de la violencia en la construcción de llaneridades}

\section{- ¡Que cada bala sea un velorio...!}

Esa frase la dijo Carrao una tarde mientras conversábamos con Ramón y otros vaqueros, sentados en la parte de atrás del hato de Matarrala, en San Martín de los Llanos bajo la sombra de uno de los centenarios mangos que rodean la casa. En esta parte están los dormitorios de los propietarios y de los estudiantes de universidades que cada tanto van a realizar observaciones de animales en la mata de monte que comprende las tres mil hectáreas de selva compartida con el vecino hato El Venado, convirtiendo a estas dos propiedades en una reserva natural.

\footnotetext{
Forma de enunciación usada a manera de refrán popular por los vaqueros, a través de la cual se experimenta un sentido pragmático con relación a la vida y la muerte en la cotidianidad de las relaciones sociales entre los vaqueros. Este artículo de reflexión es producto de la investigación ganadora de la beca de los "Fondos concursables para la salvaguardia del patrimonio cultural inmaterial de América Latina del CRESPIAL" en 2016, titulada "Los cantos de trabajo de llano en la Serranía del Manacacías", otorgada a su autor.
} 
La conversación se había tornado fuerte: Carrao, forjado en el "trabajo de llano" como obrero y caporal; Ramón, heredero de una familia de terratenientes que ha vivido en la Serranía desde el siglo XIX. Hablaban con el calor que da el recuerdo de hechos dolorosos, en medio de ese llano que no es llano porque no es plano, es serranía (figura 1), altillanura o, como se designa en Rausch (1994), ese llano de arriba, porque está más próximo a la cordillera oriental, pero que es reconocido como llano por la ganadería extensiva, por las prácticas y los modos de vida de estos "llaneros" que los caracterizan y los conectan con los araucanos y los casanareños que habitan esos llanos de abajo, caracterizados también en Rausch (1994), y que son representantes del imaginario de llaneridad, consolidando conceptos que nos hablan de los procesos de identificación y de la identidad como un acto performativo siempre en proceso (Hall, 2010), que nunca termina y que además no es situacional (Hall, 2003); que se desliga de un paisaje o un lugar exclusivo de fronteras definidas, que presenta límites borrosos o desdibujados (Frith, 2003). Todo esto se iba descubriendo a través de los relatos de un lado y de otro.

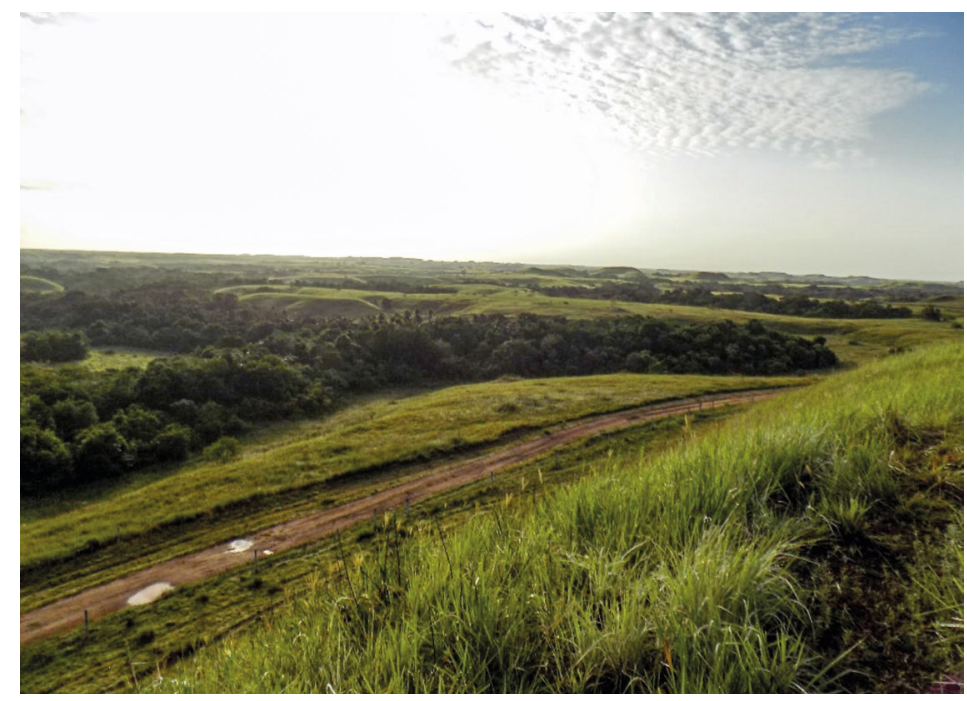

Figura 1. Camino ganadero y paisaje de serranía. Fuente: archivo personal del autor.

Hablábamos de los caminos que conectan al municipio de San Martín de los Llanos con los hatos ganaderos que desde hace centurias han existido en la serranía del río Manacacías y en sus alrededores. Estos caminos han sido elemento fundamental de "todo el desarrollo poblacional del centro del país, incluida la meseta cundiboyacense [...]", en otras palabras, la construcción del Estado Nación colombiano "giró en torno a los caminos que de Bogotá llegaban al Magdalena por Viotá o 
Guaduas, o comunicaban la Capital con los Llanos" (Salazar, 2000, p. 2). Es así como "la colonización de los territorios bañados por el Arauca, el Meta y sus afluentes, Cravo Sur, Pauto y Casanare, se realizó por medio de encomiendas y surgió de las necesidades de comercio entre los Llanos y el altiplano" (Salazar, 2000, p. 5). Entonces, desde épocas coloniales hasta nuestros días estos caminos han permitido a cientos de vaqueros de la serranía como Carrao, llevar miles de cabezas de ganado hacia el principal mercado ganadero del departamento del Meta -San Martín de los Llanos-, para ser engordadas en los cebaderos cercanos al pueblo y posteriormente vendidas en Villavicencio y Bogotá.

Muchas funciones han cumplido estos caminos. Permitieron conectar el mundo indígena guayupe y saes del Meta con el mundo muisca de Boyacá y Cundinamarca, en épocas prehispánicas; permitieron también llevar hasta estos territorios a conquistadores tras el sueño de El Dorado y, una vez desvanecida tal ilusión les permitió dejar allí "a unos cuantos intrépidos encomenderos, misioneros y estancieros con el encargo de crear una extensa zona de frontera" (Rausch, 1994, p. 38). Más tarde, estos caminos permitieron conectar un activo comercio entre los hatos ganaderos creados por las misiones en las regiones de Arauca, Casanare y Meta con la zona de los grandes centros poblados del altiplano andino especialmente Sogamoso, Tunja y Bogotá a través de Cáqueza (Rausch, 1999). Este gran proceso de desarrollo ganadero llevaría a la creación de grandes latifundios que han permanecido hasta nuestros días.

A través de estos caminos se permitirían también, en un pasado más reciente, llevar hasta estos solitarios territorios el progreso, las maquinarias, la salud, los colonos, las petroleras, las empresas palmeras y la consolidación de grandes terratenientes propietarios de los hatos de la primera mitad del siglo XX - como los antepasados de Ramón-. En la década de 1960, los caucheros, los coqueros y cultivadores de marihuana llevarían nuevas formas de violencia a estos territorios, también a través de estos caminos. Es importante hablar por tanto de las dobles o múltiples caras de todos estos caminos que llevan y traen o, que no permiten llevar ni traer, que aíslan. Caminos que dominan, que dan poder, que acortan distancias o que abrevan el ganado en la cotidianidad del oficio de los vaqueros de la Serranía.

También hay caminos agentes de desgracia cuando se quiebran los códigos consuetudinarios y sobrevienen los conflictos a causa de estos quebrantos; caminos pacientes del progreso. Progreso cientos de veces objeto de discursos del Estado-nación desde hace más de 200 
años. Hablábamos también de los caminos agentes del poder y del control de un territorio geográfico constituido por más de 15 mil kilómetros cuadrados, incluyendo principalmente el municipio de San Martín de los Llanos y áreas pequeñas de diez municipios aledaños. Caminos que desde que hay memoria han atravesado los territorios aledaños a San Martín de los Llanos en el Meta; de eso hablábamos cuando Carrao dijo esa frase:

- ¡Que cada bala sea un velorio!

Frase que me habitó durante innumerables cavilaciones, porque enmarca una historia y una realidad; porque golpea como un balazo; porque sintetiza el sentido, la memoria y las prácticas consuetudinarias que han desarrollado gran parte de las personas que habitan estos caminos y que han sobrevivido estos territorios de serranía; porque pareciera que sintetiza, en gran parte, las problemáticas de la ruralidad colombiana; porque está metida en las voces de la gente, en la cotidianidad $\mathrm{y}$, porque es avalada con el poder universal, transversal y analógico que tiene un refrán popular; porque ya ha sido consensuada socialmente y determina una forma de pensamiento y de acción para la adaptación y la supervivencia en un contexto; porque "el que dispara primero, dispara dos veces", porque "en el llano muchos nacen y pocos se crían", me dicen ellos, los vaqueros, y lo he escuchado desde siempre en este territorio. Porque "el que reza y mata empata", pareciera que también quieren decir ellos y lo pienso durante los días posteriores a aquella tarde y a otros encuentros cuyas vivencias y relatos aquí compilo y analizo. Porque la muerte ronda en este territorio sin Estado, porque las balas agencian muerte y son índices de poder. Porque ellos -los vaqueros- viven justo en la mitad, entre el poder y las balas, como los artistas para Gell (2016), ejerciendo una espera, separados por un tiempo incierto de esa bala marcada con su nombre. Para ellos el velorio y las balas constituyen el fin de la vida en una construcción directa y pragmática que han aprendido de la experiencia, de la vida y la muerte.

La bala, objeto de muerte y poder, determinante para la solución y generación de conflictos en la memoria del territorio. Antiguamente, cuando alcanzaban los quince años de edad era casi una ley que los padres compraran un revólver a sus hijos, cuentan los vaqueros. El revólver, símbolo de hombría, de poder y de la virilidad prototípica de aquel mundo, que el adolescente debía portar para acceder a aquello a lo que solo un hombre podía aspirar en un mundo hecho "para varones con los huevos bien puestos" dice Carrao, para ascender en una jerarquía llena de iniciaciones y desafíos. 
En este universo cultural las balas han dado el poder, han permitido dispensar muerte, perdón o justicia, han sido herramientas al servicio de los hombres y de las circunstancias, balas Estado, sucedáneas de un Estado inexistente o invisible en un territorio cuyo control y propiedad se disputa día a día. El velorio, uno más de tantos rituales de relación con la muerte en un mundo que demanda valentía, pero que llena sus cementerios con nombres de valientes. Las balas viajan buscando muerte porque solo así proveen poder y respeto, porque esa es su naturaleza, para ello fueron hechas, para ello son disparadas y no se puede traicionar esa naturaleza de las balas, porque "si lo saca es pa' usarlo", cierra Carrao.

\section{Recorriendo el camino ganadero: activando la memoria}

Un mototaxista que trabaja en el pueblo tiene las llaves del candado que permite el paso a los caminos que atraviesan las tierras de diversos dueños, en calidad de servidumbre, para poder llegar al hato Matarrala, a donde me dirijo. En varias ocasiones han querido abrir una carretera pública que conecte las tierras de los hatos vecinos con el camino real. Pero el riesgo es difícil de prever. Ya se han declarado como reserva y esto traería, entre otras problemáticas, cazadores y todo tipo de oportunistas que podrían aprovechar la facilidad en el camino de libre acceso para adentrarse en la mata de monte.

Esto se observa con solo alejarse del entorno urbano de San Martín de los Llanos siguiendo lo que dos décadas atrás era el camino ganadero. Hoy son pocos los ganados que llegan al pueblo arreados, porque en su mayoría llegan en camiones. Los caminos conectan y aíslan, también se transforman para dar paso a otros oficios y prácticas, para declarar obsoletas otras. "El ruido de los camiones enterró el canto del cabrestero" (Ministerio de Cultura, 2013), recuerdo esta frase de un vaquero araucano, al hablar de las amenazas de la manifestación.

Los empresarios que sembraron miles de hectáreas en los alrededores de San Martín se han visto en la necesidad de poner asfalto a esta vía para transportar mejor el aceite de palma de la procesadora que han montado. Ya no necesitan sacar más semilla, sacan solamente los carrotanques llenos de aceite directamente de las plantas donde procesan este producto para toda clase de usos industriales. 
Hay cientos de hectáreas de cultivos tecnificados de patilla y arroz, dependiendo del momento del año. Se ve a los lejos la sombra de unos corrales; allí había sido una de las principales posadas adonde llegaban los vaqueros antiguamente, antes de que hubiese carretera; allí encerraban el ganado y dormían, otros se iban directo al centro del pueblo e iniciaban sus correrías de cantinas y mujeres, a esperar que se iniciara una nueva travesía con ganado. Ahora solo se ve que la alta hierba invade las corralejas y, que la manga de embarque ya no se utiliza. Son solo huellas del pasado, el territorio como un palimpsesto, texto sobre texto, producto de la superposición en las capas del tiempo (Prósperi, 2016), que se dejan leer en el paisaje y que narran este territorio; lugares que evocan recuerdos a vaqueros y caporales y, a quienes vivieron esta historia. Ellos pasan por estos lugares y hablan de sus experiencias, presa de nostalgias. El viaje como activador de la memoria va reconstruyendo el territorio a través de relatos, en cada curva del camino; la metodología más simple pero más eficaz en este trabajo, que voy descubriendo también por el camino.

El mototaxista no ha formado parte de esa capa temporal de viejos vaqueros y de grandes hatos; él también ha sido paciente de poderosos agentes locales como los cultivos de palma y las petroleras que hoy reconfiguran este paisaje y generan un espejismo económico que es efecto del tentáculo del progreso prototípico del Estado-nación.

Más adelante el camino pasa por una de tantas selvas de palmeras (figura 2); es el gran cultivo de palma de aceite que se ha tomado la región desde hace tres décadas sin respetar nada ni a nadie. Las sabanas libres y el camino abierto se han cerrado. La trocha ganadera se ha encamellonado con cercas. La palmera como una gran boca, bebe las aguas del río Camoa y del río Cumaral, y de muchos otros ríos de la Serranía. Deglute sabanas de vegetación nativa que produce ganancias a sus accionistas y defeca terrenos estériles a los lugareños, salpicando miserias de las que sobreviven las pacientes migraciones de negros del Cauca y el Chocó. Migraciones que son agenciadas por estas inconmensurables selvas del capitalismo. 


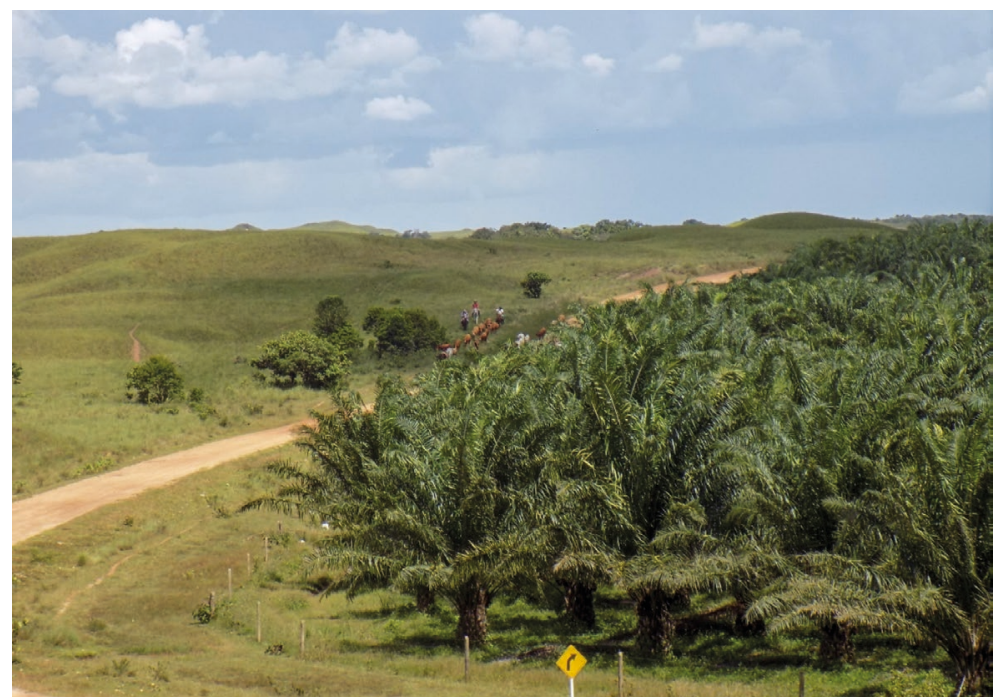

Figura 2. Camino ganadero "encamellonado" de un lado por la cerca del monocultivo palmero.

Fuente: archivo personal del autor.

Estos cultivos son motores de desplazamiento de población afro, víctima de esa otra violencia silenciosa que es el desempleo. Los habitantes lugareños no suelen emplearse en las palmeras, es considerado duro y mal pago, dicen los vaqueros. El del mototaxi dice: -yo prefiero seguir trabajando con la moto. Mi hijo también trabaja conmigo, él tiene su propia moto ya, así nos va mejor que trabajándole a esos palmeros-. Sin embargo, estas selvas de palma de aceite encuentran sus destinatarios en las poblaciones presa de grandes necesidades económicas, principalmente en el Pacífico colombiano. Ellos dejan su tierra para irse con sus familias a estos territorios desconocidos y emplearse en los cuidados y recolección de frutos de palma, estableciendo barrios a las afueras de los pueblos. Usualmente solo trabaja el padre y los hijos mayores. Algunas madres preparan alimentos y bebidas para vender en las plazas de los pueblos, que de repente se han llenado de población afro.

Por esta ruta llegaban ganados desde el municipio de Puerto López y desde algunos hatos lejanos como El Toruno, Chiriguare, Caneyes y otros que aún producen ganado y utilizan cada tanto el camino como forma de transporte para arrear el ganado hasta las inmediaciones de San Martín. A lado y lado del camino se observan huellas del pasado que hablan del espíritu del lugar. Broches grandes de hasta ocho o diez metros de anchura con sus largas callejuelas pensadas para llevar el ganado. Servían de entrada antiguamente a todas las fincas, hechos de siete alambres de púa y maderas delgadas de travesaños, que permiten abrir y cerrar, incluso 
sin desmontar del caballo. Hay otras huellas menos felices, como las casas abandonadas a causa de la última violencia (figura 3), la del 2004-2010. Con sus anillos de alambre en los árboles circundantes (figura 4) a donde los paramilitares colgaban y torturaban a sus habitantes durante la guerra.

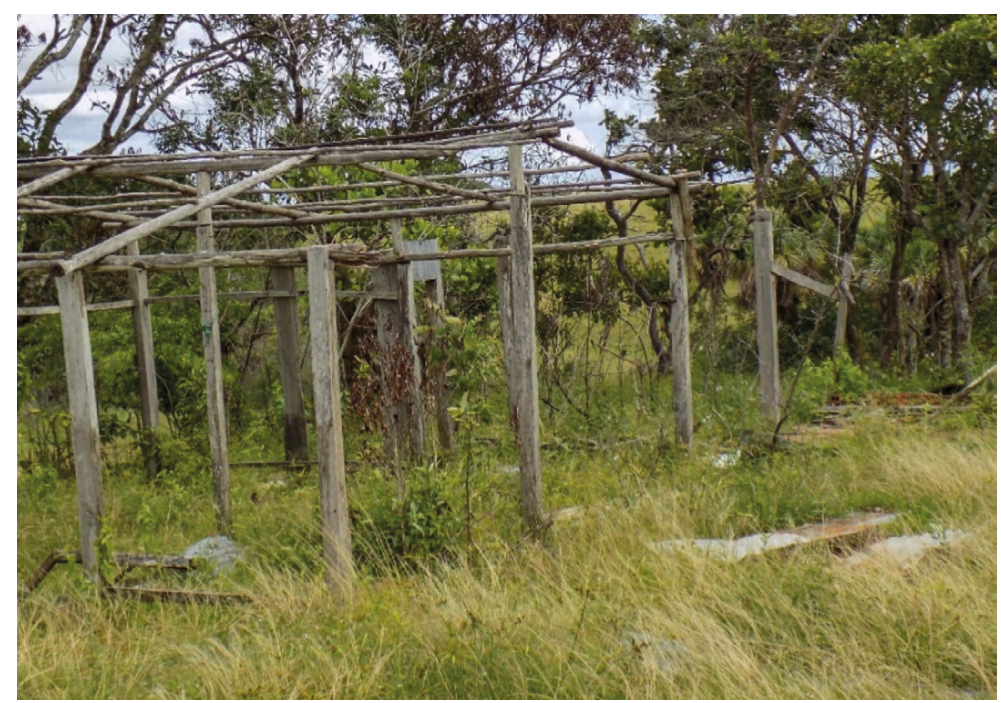

Figura 3. Casas abandonadas a causa de la guerra.

Fuente: archivo personal del autor.

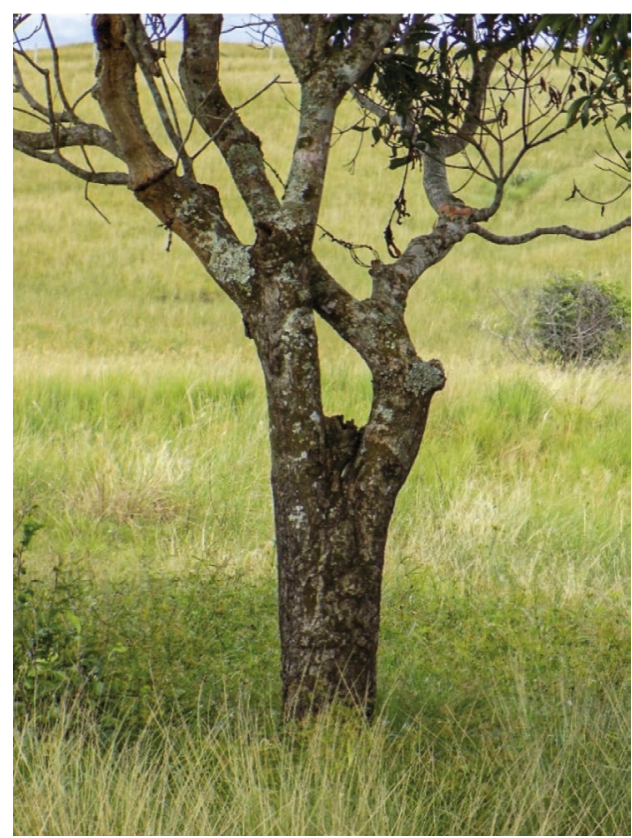

Figura 4. Anillos de alambre, huellas de la guerra.

Fuente: archivo personal del autor. 
Unos potreros pradizados con pastos de engorde son, para un vaquero, espacios que demandan ganados para ceba, que a su vez son agentes de cuidados tanto para el pasto como para el ganado, y es una huella del tipo de actividad que aquí se desarrolla; indica que aún estos territorios siguen manteniendo prácticas similares a décadas atrás; que en estos hatos que vamos recorriendo se produce ganadería de calidad, para sacar directamente hacia los centros de consumo en Bogotá. Indica también que a pesar de todos los cambios que ha habido, aún se siguen manteniendo ciertas formas básicas de producción $\mathrm{y}$, por tanto unas prácticas culturales relacionadas con los efectos que la actividad ganadera ejerce sobre las personas y sobre el medio. Se evidencia que se mantiene viva una cultura: como el arreo, las sonoridades asociadas a la relación vacuno-humano y los cantos de trabajo de llano, los rezos necesarios para ciertos "males" que se resisten a las drogas veterinarias, los conocimientos sobre hierbas medicinales, la gastronomía centrada en las vacas y sus derivados, la cotidianidad laboral del hato con sus pequeños rituales matutinos demandados por caporales y vaqueros, las mañanas de ordeño, el "trajín con los caballos", y todo un mundo de objetos asociados que no viene al caso enumerar y, que en su conjunto conforman un mundo de pequeñas redes de relaciones en múltiples direcciones, que se materializan en objetos elaborados o ejecutados por los artistas y artesanos que son los vaqueros y los caporales, en cada uno de los hatos y fundos de este territorio.

En medio de una leve oscuridad, al lado izquierdo del camino, veo acercarse hacia nosotros la sombra de una construcción. Está abandonada desde hace unos veinte años. Desde mis anteriores viajes a Matarrala me ha llamado la atención aquel recinto solitario y por tanto he averiguado su historia. Se trataba de la escuela de La Unión en la década de los noventa (figura 5).

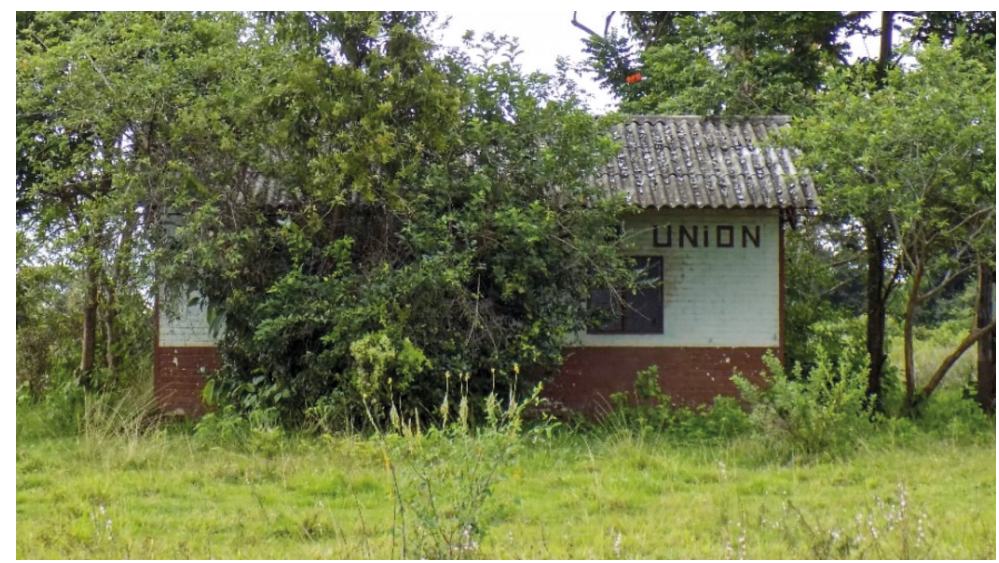

Figura 5. Escuela de La Unión.

Fuente: archivo personal del autor. 
Hoy día la gente pasa por el camino evitando voltear a verla durante las noches. Es un espacio siniestro, es un índice de la violencia prototípica colombiana, una obra de las balas, de la muerte. Un espacio cargado de significados tanto para familiares de víctimas, destinatarios directos, como para pacientes indirectos obligados a experimentar su efecto, como nosotros, solo por tener que pasar por el frente, conociendo sus relatos.

Durante los años noventa los paramilitares llevaron a un grupo de personas a La Unión, los fusilaron y los desmembraron, dejando sus cuerpos regados por todo el lugar. Desde entonces la escuela tomó ese carácter para la gente y se siente al aproximarse a su entrada. Nadie quiso siquiera volver a este sitio. Dicen que se ha hecho inhabitable y las personas que se arriesgan a entrar, ven sombras que caminan por sus corredores y escuchan lamentos de personas en los salones de clase. "Que cada bala sea un velorio", así es y así ha sido. Cada lugar tiene una historia que nos lo recuerda, solo es cuestión de encontrar quién nos cuente el relato que buscamos para ir armando el mapa de la balas y del poder que han agenciado estos caminos que venimos recorriendo, de los velorios dan cuenta las tumbas, testigos silenciosos. Una escuela en abandono y enfrente de la escuela un camino, que aún usan los vaqueros.

Son caminos que se transforman, que han empedrado para evitar que se inunden en invierno y permitir el paso de carros. La piedra obliga el uso de herraduras en los caballos, permiten el uso de camiones que desplazan indirectamente a los caballos, que hacen, por tanto, obsoleto el oficio del vaquero, del baqueano, del posadero. Caminos que agencian "progreso" que es además, ese gran prototipo de todas las transformaciones de estos paisajes, de estos hombres y mujeres de este territorio. Progreso prototípico que se manifiesta en múltiples índices como espantos de mutilados, balas, palmas de aceite, cultivos tecnificados, petroleras (figura 6), transgénicos, nuevas formas de producción, FARC, paramilitares, más balas, lágrimas de viudas, de madres; carencia de educación. Progreso agente de escuelas fantasma que vamos dejando atrás. 


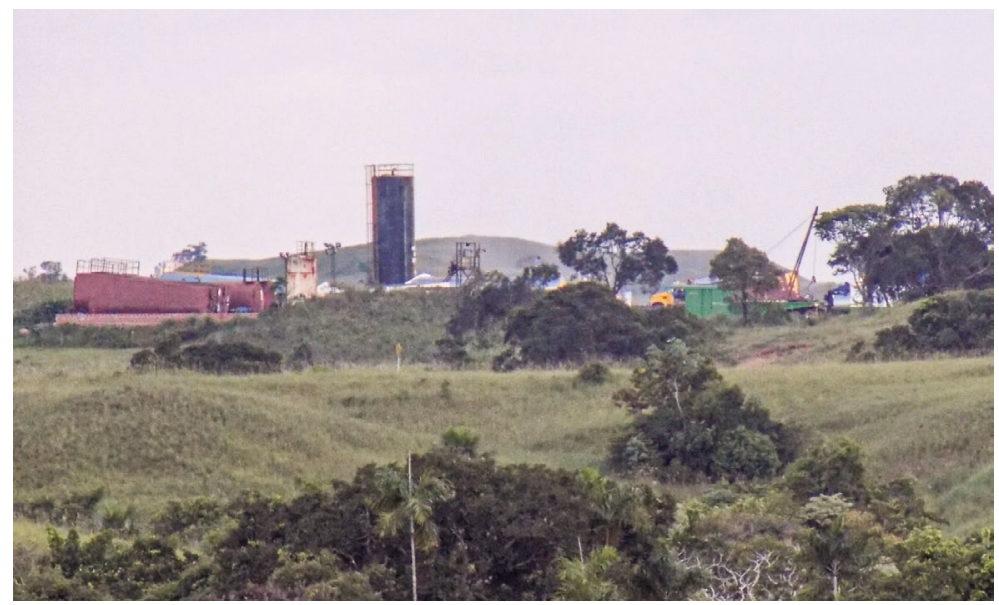

Figura 6. Campo petrolero en la serranía.

Fuente: archivo personal del autor.

Para llegar a Matarrala toca atravesar quince broches y tranqueros. Algunos de los broches tienen zanjas producidas por el intenso tráfico de caballos y vacas, por tanto es inevitable terminar con los pies hundidos hasta el fondo del barro. Al entrar a uno de los principales hatos que hay en esta ruta, conocido como El Venado, encontramos un gran tranquero con candado. El mototaxista apaga el motor para acercarme un juego de llaves, indicándome una gastada por el uso y me guiña el ojo.

- Estos caminos no son para todo el mundo - me dice.

Esa frase me queda dando vueltas, «estos caminos no son para todo el mundo»; esta frase encierra un profundo sentido con relación al camino y al territorio, y me sirve para entender lo que busco, pienso; cierro el candado con la certeza de que volveré sobre este objeto, le entrego la llave y monto en la moto de vuelta.

Matarrala es un hato principalmente de engorde (ceba) de ganado. La forma como uno lo comprueba es observando a los animales; la mayor parte de los vacunos son novillos y el pasto no es pasto silvestre, es pasto sembrado; todo esto se puede ver en lo homogéneo de las pasturas que se pueden apreciar con una rápida barrida de la vista.

Al superar el último broche, observamos el cañal y el yucal que tienen sembrado al lado del camino. En ese momento nos encontramos directamente en la cuadra de maternidad. Todos los animales grandes son vacas que recientemente tuvieron parto. Ahí permanecerán con sus crías hasta que los pequeños tengan fuerza para ir con sus madres a los 
potreros, una vez las vacas estén en condiciones físicas de amamantarlos y los hayan aceptado de buena manera. Hay madres que no aceptan a los recién nacidos y se debe proceder a criarlos con biberones. En ese caso el ternero pasa a los pequeños corrales para recién nacidos huérfanos, donde reciben cuidados especiales. En esta cuadra acechan animales como buitres y zorros que van en busca de placentas o de un débil ternero que aún no pueda defenderse.

En el corral, a unos 400 metros de este último broche, están ordeñando una vaca para darle calostro a un ternero. Ordeñan a su madre en la manga tres veces al día y tres veces al día le dan sus biberones. Allí están junto con Carrao, que es el caporal del hato, Lagrimón, el muchacho más joven y aprendiz de las faenas, y Juancho, un vaquero de mediana edad. La cocinera llama al desayuno y caminamos todos hacia la casa del hato.

\section{Candados y caminos}

En la gran cocina, junto con los trabajadores y en diferentes momentos del día, tomamos tinto. Pareciera haber sido construida para departir luego de las largas faenas de trabajo; allí, siempre hay tres termos grandes llenos de café cerrero (fuerte y sin dulce). Es el espacio que ejerce una fuerza especialmente compleja para todos. Ahí nos reunimos a contar historias y a hablar de lo que se hizo durante el día, es un lugar de reflexión. Se realiza solamente allí alrededor del tinto caliente. Todos sabemos que ese es el espacio para ello y nadie tiene que explicarle esto a nadie. Yo lo aprendí desde la primera vez que fui a Matarrala, hace más de cuatro años a participar de la capada de unos mautes para ceba. Una vez uno se levanta de aquel lugar debe darse a la acción, cumplir un rol en el trabajo.

Los trabajadores se llaman por apodos, "Mico" es uno de ellos. Está muy bien puesto, pienso, cuando lo veo, aún sin saber que es él. Hay un prototipo de un mico en la mente de nosotros y este trabajador de llano es un índice perfecto, su cara representa a este animal y demanda por tanto la necesidad de llamarlo "Mico"; es uno de los trabajadores más antiguos del hato. También suelen usar sus apellidos, un tanto como en la milicia.

La lluvia no cesa. Desde hace tres días que llegué al hato y los animales se muestran perezosos: la lora y la guacamaya están silenciosas, metidas bajo un techo, salvaguardándose del agua, y los caballos quietos, debajo de los árboles de mangos. La casa del hato es muy grande; la cocina está en la mitad de la construcción que tiene forma de Z. De base suelen 
trabajar, descontando al caporal que es Carrao, al menos la cocinera o guisa, su esposo el tractorista y su hija de cinco años; los obreros que también son vaqueros son Mico, Lagrimón, Juancho y Partagás.

Cuando hay grandes trabajos de llano esta cuenta se aumenta y llaman los vaqueros que haya necesidad de llamar. En la zona de los trabajadores hay un gran salón que es el dormitorio de ellos, allí permanecen guindados los chinchorros con sus respectivos mosquiteros. Saliendo de allí, luego de dar una curva a la derecha, está un corredor que comprende primero la zona de aperos y caballeriza, enseguida el comedor de los obreros y remata al fondo la cocina.

Al lado de la cocina está el dormitorio del caporal y el de la familia del tractorista y la guisa. Siguiendo hacia el fondo, luego de voltear a la derecha, siguen tres habitaciones para estudiantes y al fondo se remata con la sala de estar y el comedor de los "blancos", que conserva la mesa de un antiguo hato de los mismos dueños, que perdieron en la guerra, llamado Manacal.

A Manacal lo tuvieron que vender durante la violencia de los años 90; violencia siempre generadora de cambios en el territorio y causa de actividades como el narcotráfico. Lo vendieron (bajo amenazas) justo a un narcotraficante porque en ese contexto de violencia solamente personajes siniestros son clientes para adquirir tierras en medio de las balas. La violencia agencia más violencia, y las balas agencian más balas, más actividades ilícitas que florecen alrededor de todo esto, multiplicando muertes, sinónimo de velorios para los vaqueros, que deberían hacer del negocio de los oficios y objetos rituales de muerte, los mejores negocios del pueblo.

Durante mi última estancia en Matarrala, en la sala de estar del fondo me reúno con la dueña del hato, con Ramón el de El Venado, con Carrao el caporal, con El Paisa, Juancho y alguno que otro que participa intermitente, justo dos días antes de volver a Bogotá. La llovizna suave ameniza las palabras de unos y otros. El invierno en la serranía evoca la nostalgia, la melancolía del lugar y las vivencias del pasado.

Carrao y Ramón cuentan la historia del camino que conduce a El Venado y Matarrala desde el camino real, cuentan la historia del candado sin que yo haya referido el tema siquiera, y sonrío para mí, recordando cuando lo abrí y lo cerré para pasar con el del mototaxi muchos días atrás, en otro viaje de los muchos que intento condensar en este escrito. 
-El candado no significa exclusividad, no es un lujo como muchos lo catalogarían -dice Ramón.

Desde que decidieron proteger la reserva, tuvieron que empezar a restringir el paso por el camino principal para proteger lo poco que viene quedando de selva natural.

Durante la violencia de los años 90, era común que llegaran camionetas llenas de gente armada. Una vez solicitaron el paso por El Chunaipo, y lo hicieron a nombre de alguien a quien se referían como "el patrón". Comprensible porque este es el principal río que atraviesa las tierras de Matarrala; si se tiene el dominio de este paso sobre el río, se puede ir a gran parte de la serranía del Manacacías, logrando realizar la travesía por el camino ganadero sin dar las vueltas de la carretera principal y al resguardo de las miradas vigilantes de las autoridades.

Carrao les habló de la manera más calmada posible, porque, justo en ese momento no había nadie más en el hato y los tipos estaban de mal carácter.

-Si ustedes quieren pasar por ahí, van a pasar, ustedes tienen las armas, yo no; pero quiero que quede claro que no estamos de acuerdo con que esto suceda -les aclaró Carrao.

-Nosotros no solo queremos el permiso, necesitamos que nos preste sus herramientas para hacer el paso para las camionetas en el ríocompletó el cabecilla.

El paso fue construido con ayuda de los obreros del hato y durante seis meses pasaron camionetas entre el Guaviare y San Martín por esa parte del camino ganadero. Nunca se pudo comprobar qué transportaban pero todos sabían que era droga. Los caminos ganaderos de la serranía del Manacacías eran la ruta de conexión clandestina con San José del Guaviare. Pasaban y dejaban los broches abiertos, se perdía ganado, amenazaban, asesinaban y quemaban camionetas para desaparecerlas a lo largo de todo el camino ganadero. Cruzaban el río Chunaipo y muchos otros ríos en otros hatos, hasta llegar al Manacacías y hacia el sur, al Guaviare.

Era la época de Pedro Oliverio Guerrero Castillo alias "cuchillo" quien junto con su hermano Dúmar Jesús Guerrero alias "carecuchillo", fueron los primeros hombres que trabajaron con Gonzalo Rodríguez Gacha y, que conformaron grupos paramilitares especialmente en el Guaviare y el Meta, llegando a constituir el bloque Centauros. Después de que cayeron 
los grandes capos y se desmovilizó este bloque, "cuchillo" y su hermano tomaron la región de la serranía del Manacacías constituyendo el Ejército Revolucionario Popular Antiterrorista Colombiano -ERPAC. Con ese grupo armaron a 1100 hombres y, entre los años 2004 y 2009 terminaron de disputar el territorio a las FARC y a los dos grupos paramilitares locales liderados por Héctor Germán Buitrago, alias "Martín llanos" y Miguel Arroyave, líder del grupo paramilitar Los Arroyave (Revista Semana, 2010), que fueron el mal común en los caminos ganaderos del Manacacías y San Martín de los Llanos. Este camino ganadero a lado y lado, por donde quiera que se recorra, está sembrado de huellas de guerra. Entre los principales crímenes estaban la desaparición, desplazamiento forzado, masacre y tortura a campesinos y narcotráfico.

Comenta Ramón: esa tarde estaba solo en El Venado, el encargado del hato había salido para la sabana. Escuché los motores de las camionetas que venían a lo lejos, de aquí del lado de Matarrala. Monté rápido mi caballo y fui a anticiparles la llegada al portón metálico (el del candado). Llegué antes que ellos. Venían dos camionetas Toyota que pararon en frente del portón. Nadie se bajó, nadie me dijo nada. Me bajé del caballo y caminé hacia la ventana del conductor de la camioneta de adelante; era un tipo con dos mujeres jóvenes que lo acompañaban. Los de la camioneta de atrás eran todos hombres y tenían ametralladoras. Yo sabía que estaba jugando con la muerte, pero no podía seguir permitiendo que tuvieran el camino como un paso real para sus correrías. Ya empezábamos a figurar como cómplices en la región.

-Vea señor, quiero pedirle algo, de hombre a hombre, teniendo en cuenta que somos hombres con respeto por el otro y con honor. El paso de ustedes por estas tierras nos está trayendo muchos problemas, le pido comedidamente que no vuelvan a pasar por aquí -le solté al tipo, mirándolo a los ojos, muy de cerca para que no pudiera sorprenderme, mientras apretaba con mi mano derecha el 38 de cañón corto, con el dedo en el gatillo, dentro del bolsillo de mi pantalón. Sabía que en cualquier momento se podía armar y estaba decidido a morir llevándome al menos a uno de ellos. Por eso estaba armado, si no, no habría ido con el revólver.

El tipo no dijo ni sí, ni no. Uno de los de atrás se bajó, abrió el portón, pasaron y se fueron. Nadie me respondió nada y me quedé ahí parado, mirando. Al siguiente día puse el candado y así fue como cerré el camino.

A las pocas semanas de esto, estoy en San Martín. Un tipo que se me acerca me dice: 
-El patrón lo está buscando.

-Yo no sé quién es su patrón -respondo.

- ¿No se acuerda del otro día en el portón? Yo estaba en la camioneta de atrás. Usted le habló muy feo al patrón ese día, está molesto con usted.

-Bueno y ¿Quién es ese "patrón" suyo entonces?

-Pues Cuchillo, papá. Usted le prohibió el paso por el camino a Cuchillo -me responde el tipo y a mí me pasa un sudor frío por el cuello en ese momento.

-El patrón necesita entonces que usted me entregue la llave del candado que puso porque él va a seguir pasando por el camino.

Meto la mano al bolsillo, saco la llave, se la alargo, el tipo tira a cogerla y yo se la quito en el último segundo. -le digo.

-Espere, primero hagamos algo, deme usted las llaves de su casa

El tipo arruga el ceño y me dice que si estoy loco. A esto le respondo:

-Vea señor, así como usted no me da las llaves de su casa, yo tampoco le puedo dar las llaves de la mía a su "patrón". Entonces dígale que cuando él me dé las llaves de su casa, yo entonces le daré las del portón de entrada a la mía.

El tipo no sabe qué hacer, se ve visiblemente incómodo, y me dice que piense bien lo que hago. Que ese día que les salí al portón el patrón me iba a matar, pero que ahí iba "Carecuchillo", su hermano, y que se acababan de repartir el territorio: "Cuchillo" se había quedado con el Guaviare y el hermano con el Meta, por tanto ya estaba a cargo el hermano y él no había permitido que me mataran. Le debo mi vida entonces al hermano de "Cuchillo" - pienso. A los tres meses lo mataron y tiempo después moriría el propio "Cuchillo", en ese operativo que ya conocemos. Soy un sobreviviente, las balas no fueron velorio, en esta ocasión.

Todos estamos en vilo escuchando este relato del camino ganadero. Ya Ramón había contado muchas historias como esta, ya El Paisa había relatado su parte, ya Partagás, ya todos habían aportado sus relatos, sus recorridos por el camino ganadero, pero es en ese preciso instante en que Carrao suelta la frase que motivó este escrito, que nos disparó a todos en 
medio de los ojos de manera súbita, y ante la cual también repetí, asintiendo sin lugar a dudas, junto a todos los demás:

- ¡Que cada bala sea un velorio!

\section{Reflexiones finales}

"Que cada bala sea un velorio"; cuando un vaquero enuncia esta afirmación se está refiriendo de forma pragmática a la muerte, a dejar de existir, a que cada bala cumpla su cometido. El velorio no es más que una forma de hablar de la muerte sin ir hasta lo ritual. De que cada bala sea o no un velorio, depende que puedan seguir siendo llaneros, vaqueros, finqueros, padres y, quizás, llegar a abuelos y querer y poder seguir transmitiendo sus saberes y prácticas a nietos e hijos. También desde esta enunciación a manera de refrán popular se refleja un tipo de incorporación de la violencia a lo ordinario; "la violencia en la vida diaria como el eje desde el cual se articulan los sentidos y representaciones que dan forma a la cultura" (Espinosa, 2009, p. 107) y a lo cotidiano de la vida rural de los vaqueros.

Quizás en estos contextos la violencia no ha sido suficientemente leída e interpretada a través de lógicas culturales locales, cotidianas y específicas. Así lo manifiestan ellos, los más viejos cuando se les pregunta: ¿por qué prefieren que sus hijos se vuelvan profesionales y se vayan a la ciudad a vivir? La violencia es una de las más fuertes y gigantescas amenazas para la permanencia y transmisión de las prácticas culturales de la ruralidad colombiana. Por todo esto y con toda seguridad por mucho más: ¡que cada bala sea un velorio!, como dijo Carrao, casi con rabia y todos los demás asintieron, sin más.

\section{Referencias}

Espinosa, N. (2009). Etnografía de la violencia en la vida diaria. Aspectos metodológicos de un estudio de caso. Informe de investigación. Universitas humanística, (67), 105-125.

Ferro, G. (1994). A lomo de mula. Bogotá D.C.: Fondo Cultural Cafetero.

Frith, S. (2003). Música e identidad. En S. Hall, y P. du Gay, Cuestiones de identidad cultural (pp. 181-213). Buenos Aires: Amorrortu.

García, M.A. (2012). Etnografías del encuentro: Saberes y relatos sobre otras músicas. Buenos Aires: Ediciones del Sol.

Gell, A. (2016). Arte y agencia. Buenos Aires: SB. 
Hall, S. (2003). Introducción: ¿quién necesita "identidad"? En S. Hall, y P. du Gay, Cuestiones de identidad cultural (pp. 13-39). Buenos Aires: Amorrortu.

Hall, S. (2010). Sin garantías: Trayectorias y problemáticas en estudios culturales. (E. Restrepo, C. Walsh, y V. Vich, Edits.) Popayán, Colombia: Envión.

Hoffmann, O. (2000). La movilización identitaria y el recurso de la memoria. Recuperado de https://halshs.archives-ouvertes.fr: https://halshs.archives-ouvertes.fr/halshs -00463463/document

Malosetti-Costa, L. (2016). Alfred Gell, Arte y Agencia. Una teoría antropológica. Caiana. Revista de historia del arte y cultura visual del Centro Argentino de Investigadores de Arte (CAIA)(8), 168-170. Recuperado de http://caiana.caia.org.ar/template/ caiana.php?

Mantilla, H. (2017). Diccionario llanero. Villavicencio: Entreletras.

Ministerio de Cultura. (Productor), y Ramos, C.N. (Dirección). (2013). Cantos de trabajo del Llano - Urgencia [Película]. Colombia. Recuperado de https://www.youtube.com/ watch?v=ZSNPc-izsWw

Plan Especial de Salvaguardia de Carácter Urgente. (2013). Recuperado de http://www. mincultura.gov.co/prensa/noticias/Documents/Patrimonio/15-Cantos\%20de\%20 trabajo\%20de\%20Llano\%20-\%20PES.pdf

Prósperi, G.O. (2016). El texto como palimpsesto. Reflexiones en torno a la lectura literaria. Revista Chilena de Literatura, (93), 215-234. Recuperado de https://scielo.conicyt.cl/ pdf/rchilite/n93/art11.pdf

Rausch, J. (1994). Una frontera de la sabana tropical, los llanos de Colombia 1531-1831. Bogotá D.C.: Banco de la República.

Rausch, J. (1999). La frontera de los llanos en la historia de Colombia (1830-1930). Bogotá D.C.: Banco de la República / El Áncora.

Revista Semana. (29 de diciembre de 2010). ¿Quién era alias "cuchillo"? Recuperado de https://www.semana.com/nacion/articulo/quien-alias-cuchillo/126558-3

Salazar, J. (2000). De la mula al camión, apuntes para una historia del transporte en Colombia. Bogotá D.C.: Tercer Mundo S.A.

Santamarina-Campos, B. (2013). Los mapas geopolíticos de la UNESCO: entre la distinción y la diferencia están las asimetrías. El éxito (exótico) del patrimonio inmaterial. Revista de Antropología Social, 22, 263-286.

UNESCO. (2017). https://ich.unesco.org. Recuperado de https://ich.unesco.org/es/USL/ cantos-de-trabajo-de-los-llanos-de-colombia-y-venezuela-01285 